\title{
Quasi-Communication Interaction Aspects In Early Ontogenesis
}

\author{
A.A. Petrova \\ Volgograd State University \\ VolSU \\ Volgograd, Russia \\ petrova.anna@volsu.ru
}

\author{
N.A. Sytina \\ Volgograd State University \\ VolSU \\ Volgograd, Russia \\ n.sityna@volsu.ru
}

\begin{abstract}
The current paper deals with communication in early ontogenesis from the reference perspective. The material consists of recordings of German speaking adults and children, aged 2.0-2.5. After studying the transcripts, quasi-discourse is elicited. The dialogue units of quasi-discourse in child speech present quasi-responses. Since quasi-responses acquire some pragmatic meaning, it brings pseudo-communication. The authors claim that quasi-responses are manifested in intonation by the combination of the duration, intensity and the pitch of tone. Quasi-responses are initiated by children as a way to encourage a contact. The dialogue stagnation is repaired by cross-reference.
\end{abstract}

Keywords-early ontogenesis, quasi-discourse, phatic function of quasi-responses in dialogue, acoustic analysis of the dialogue responses, communicative failures, dialogue stagnation, reference and cross-reference, anti-deprivation.

\section{INTRODUCTION}

Communication is a complex process which involves verbal and nonverbal means of communication with regard to the social context. The large body of recent research has shown that the role of language means in the speech models of communication is exaggerated [1-10]. In other words, one needs to consider the speech behavior of people in various contexts. Consequently, people's behaviour, the particular situation, the social context and psychological guidelines determine the modes of speech.

Child speech is even a more complex process than adult speech as motivation appears to be hidden during interaction [11-16]. It results in "pseudo-communication" or "quasicommunication" with its quasi-remarks: quasi-questions and quasi-statements which have their pragmatic meaning of quasi-understanding or quasi-misunderstanding. The purpose of the paper is to investigate the quasi-discourse in ontogenesis and find out extra linguistic causes determining quasi-communication. Let us assume that the components of a dialogue (responses/remarks) which are understood as quasiresponses/remarks (child questions as well as statements) have their own speech function characteristics (intonational, structural and pragmatic).

The research approach is based on the hypotheses that: (a) quasi-responses are incorrect, sometimes intentionally wrong nominations in terms of reference when the object is denoted by a different word;

(b) declarative and interrogative responses are deprived of pragmatic function characteristics (assertion/ statement/information); the seme of requesting information becomes neutral and interrogative nature of the question is minimal;

(c) quasi-responses demonstrate emotional, antideprivation and phatic functions;

(d) quasi-responses can be manifested in intonation by the combination of the duration, intensity and the pitch of tone of the whole utterance or its components.

In dialogues, quasi-responses mostly occur in the speech of preschoolers; adults are focused on avoiding ambiguity in communication and teaching children to interact.

\section{QUASI-RESPONSES IN ONTOGENESIS: PROSODIC \\ FEATURES, PRAGMATIC PECULIARITIES AND FUNCTIONS (EXPERIMENTAL STUDY)}

The paper presents a psycholinguistic experiment which examines the relationship between the response type and the prosodic form. German speaking adults (responses E: and V :) and children (responses A :) participated in the experiment which was spontaneous as well as controlled. They were engaged in reading a picture book. The material consists of the longitudinal study of the transcripts of adult-child interactions involving children, aged $2.0-2.5$. The authors are primarily interested in whether all the participants employ the relevant references and strategies and which of them can turn the dialogue into a pseudo-dialogue. In order to investigate the pitch accents' shapes, the intonation contour and pauses, the speakers were recorded and asked to listen to the microdialogue after the recording. The structure of the dialogues was investigated relating to the pragmatic content. Quasiresponses were processed by a computer program Signalyze. 
Age period 2.0

S1. (Situation 1-(S1))

1E: // Schmetterling.(Butterfly)

2A: // Kiki / Auto?(Kiki, car?)

3E: // Js kein Auto is ein Schmetterling.

(It is not a car, it is a butterfly.)

4A: // Auto.(Car.)

5E: // Ein Eichörnchen. (A squirrel)

6A: // A/Auto. (Ca-Car.)

7E: // Ein Buch? (A book?)

8A: // Kiki.(Kiki.)

9E: // Das ist ein Buch.(This is a book.)

10A: // Kiki / Nei nei nei...(Kiki, No, no, no...)

(sehr leise)(in a low voice).

In the dialogue, the absence of the contact from the child leads to a communicative failure because the child is tired. Though the adult uses cross-reference, repeating the same referent several times, the child intentionally gives the incorrect nominations of the objects which he was familiar with.

The structure of Situation 1

EXTLIP (extra-linguistic prop)

Declarative (adult speaker E:) - referential utterance, voluntary

Declarative (child A:) - intentional quasi-response

Declarative (E:) - cross-reference

Declarative (A:) - intentional quasi-response

New EXTLIP

Declarative (E:) - referential utterance, voluntary

Declarative (A:) - intentionally incorrect nomination

New EXTLIP

Declarative (E:) - referential utterance, voluntary

Declarative (A:) - internationally incorrect nomination

Declarative (E:) - cross-reference

Declarative (A:) - intentional quasi-response

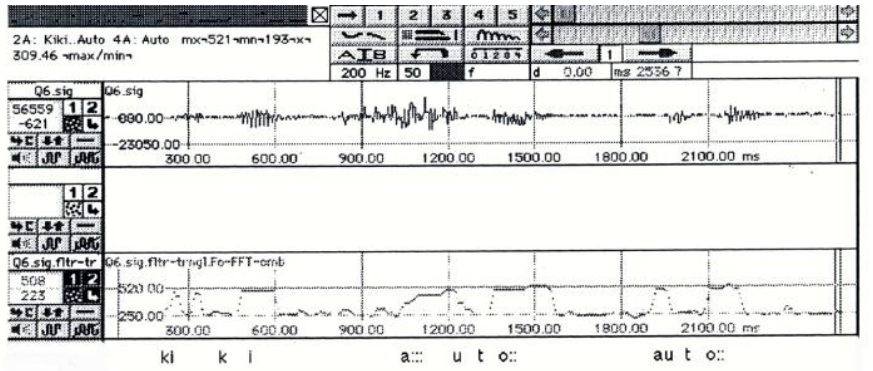

Fig1. Acoustic analysis of prosodic dialogue structure

The structure of the given polylogue demonstrates quasicommunication. At first sight, the speakers are engaged in interaction, but their responses are inadequate. In fact, the child is not interested in the exposed EXTLIP.

Intonation interpretation of dialogue responses (S1)

The micro-dialogue consists of minimal dialogue units where responses $2 \mathrm{~A}, 4 \mathrm{~A}, 6 \mathrm{~A}, 8 \mathrm{~A}$ and $10 \mathrm{~A}$ are intentionally incorrect nominations. The intonation parameters do not show contrast breaking, for example, in voice pitch frequency of nuclear syllables. The intonation contours are level without melodic contrasts. As the F0 is $\max (520 \mathrm{~Hz})$, this suggests that the responses are produced by the child rather than the adult. Though the vowels in the response (4A) demonstrate longer duration $(200 \mathrm{~ms})$ for accentless [o], there is a longer pause (about $300 \mathrm{~ms}$ ) in 2A. Nevertheless, the lack of melodic contrasts does not provide the explicit answer whether these responses are quasi-responses in terms of the intonation. Thus, the intonation accompanies the interaction and the quasicommunication is recognized by the situation itself.

Age period 2.3

S1.

E: // Und hier? (And here?)

2A: // So...(So...)

3E: // Schuhe. (Shoes.)

4A: //I! (E!)

5E: // Wieso I:? (Why E:?)

6A: // Schwein. I:... (Pig. E:...)

7E: // Schuhe. (Shoes.)

8A: //I. (E.)

9E: // Js doch nich I:.(It is not E:.)

10A: // Nein. (No.)

In the dialogue, the same object is intentionally nominated by different words (remarks 4A, 6A, and 8A). Utterance (A) is associated with the "foreign" referent, and as a result, the link "utterance - reality" is broken in the discourse medial position. The dialogue unity (DU) is interrupted by the quasiresponse "No". 


\section{The structure of Situation 1}

\section{EXTLIP}

Interrogative (E:) - encouraging nomination

Declarative (A:) - referential utterance

Declarative (E:) - confirmation of the previous remark

Declarative (A:) - spontaneous phonation-nomination, stagnation

Interrogative (E:) - follow-up question communication, incorrect nomination

Declarative (A:) - intentionally incorrect nomination, quasi-response, contradiction to the previous remark

Declarative (E:) - cross-reference

Declarative (A:) - intentionally incorrect nomination, quasi-response

Declarative (E:) - contradiction utterance

Declarative (A:) - confirmation of the contradiction utterance, self-correction

The dialogue shows that the successful communication develops only in the discourse initial and final positions. The communication is interrupted due to the intentionally incorrect child's nominations at the medial position and the interaction does not develop because there is no change in the topical focus (referent).

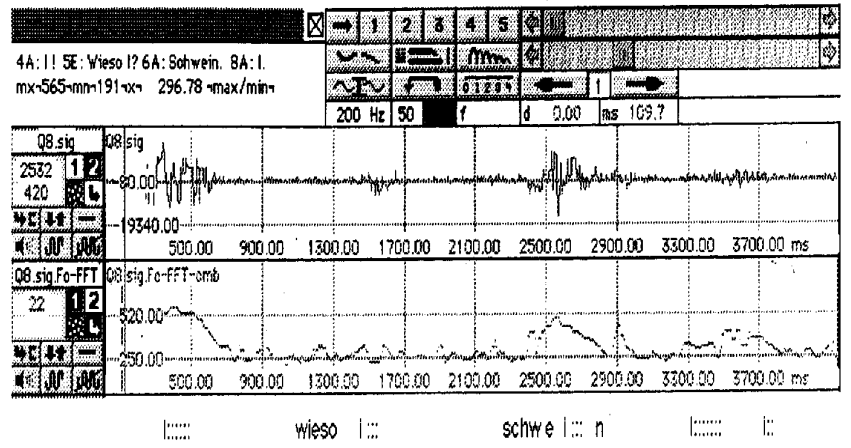

Fig. 2 Acoustic analysis of prosodic dialogue structure

Intonation interpretation of dialogue responses (S1)

The dialogue intonation contours in responses $(4 \mathrm{~A})$ and (8A) appear to be the only means of revealing pseudoresponses. Responses (4A), (6A) and (8A) have almost identical intonation contours and differ only in terms of intensity and gradual duration shortening of stressed vowel syllables. The same melodic patterns make it possible to state that the child provides intentionally incorrect nomination. Adult speaker (5E) and (9E) is trying to show the preschooler that the exposed EXTLIP is incorrectly nominated. The last response reflects the child's awareness of this fact. The longer phonation of [i] in responses $(4 \mathrm{~A})$ and $(8 \mathrm{~A})$ at different $\mathrm{F} 0$, but with the same contour shape confirms the fact of the intentionally incorrect nomination which can be also fixed by big jump-ups in voice tone (from $520 \mathrm{~Hz}$ to $270 \mathrm{~Hz}$ at the interval of $70 \mathrm{~ms}$ ). It enables one to consider the response to be a categorical assertion and it induces an adequate adult speaker reaction.

\section{S2.} this?)

1E: // Und zum Schluss was ist das? (and at last, what is

\section{A: // Gabel. (Fork.)}

3E: // Ein was? (What?)

((erstaunt))(in surprise)

\section{A: // Messer.(Knife.)}

5E: // Messer.(Knife.)

The spontaneous incorrect nomination in response $(2 \mathrm{~A})$ is manifested in the quick child's self-correction initiated by the emotional adult question "Ein was?" (What?). This question presents cross-reference, i.e. the speakers return to the same object in their sight. The communication interruption is at the discourse initial position.

\section{The structure of Situation 2 (S2)}

\section{EXTLIP}

Interrogative $(\mathrm{E}:)$ - encouraging nomination

Declarative (A:) - spontaneous referential utterance

Interrogative (E:) - cross-reference

Declarative (A:) - referential utterance, self-correction by the child

Declarative (E:) - confirmation utterance

The communication is not productive as the child's verbalization does not fit the conversation; a repair sequence follows.

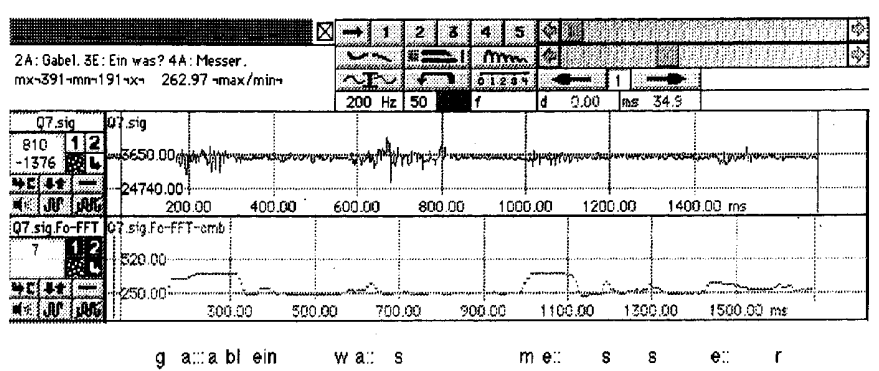

Fig. 3: Acoustic analysis of prosodic dialogue structure

\section{Intonation interpretation of dialogue responses (S2)}

Quasi-response (2A) presents the intonation contour which is the same as at the age of $2.0(\mathrm{~S} 1)$. The intonation is not the main carrier of the pseudo-response. The adult does not focus on the high speech intensity and the short duration of the stressed [a] (about $100 \mathrm{~ms}$ ) at the neutral intonation contour. Since the nomination does not correspond to the real object, it 


\section{PRESS}

determines the quasi-communication. The utterance has also average F0 (about $300 \mathrm{~Hz}$ ).

\section{Age period 2.5}

\section{S1.}

\section{A: // O: h! Ein Eimer. (O! A bucket.)}

2E: // Ein Eimer. (A bucket.)

3E: // Welche Farbe hat denn der Eimer? (What color is the bucket?)
4A: // Rot. (Red.)
5E: // Rot? (Red?)
6A: // Ja. (Yes.)
7E: // Js grün. (It is green.)
8A: // Ja.. Grün. (Yes, green.)
9E: // Ein Grüner Eimer. (A green bucket.)

The dialogue demonstrates the communicative stagnation because the word is not used correctly and the lexical unit will further occur as an intentionally incorrect nomination. It is supported by the quasi-response "Rot?/Ja" ("Red?/Yes"), which changes into "Ja. Grun" ("Yes, green") in the crossreference.

\section{The structure of Situation 1}

\section{EXTLIP}

Exclamative /Declarative (A:) - positive emotion of (A) after EXTLIP exposure: positive mental attitude to communication

Declarative (E:) - confirmation of the previous remark

Interrogative (E:) - natural change in the topical focus nomination

Declarative (A:) - referential utterance, incorrect Interrogative $(\mathrm{E}:)$ - repeated utterance, cross-reference nomination

Declarative (A:) - intentional quasi-response, incorrect

Declarative (E:) - referential utterance, correction by adult

Declarative (A:) - agreement utterance, self-correction

Declarative (E:) - correct nomination

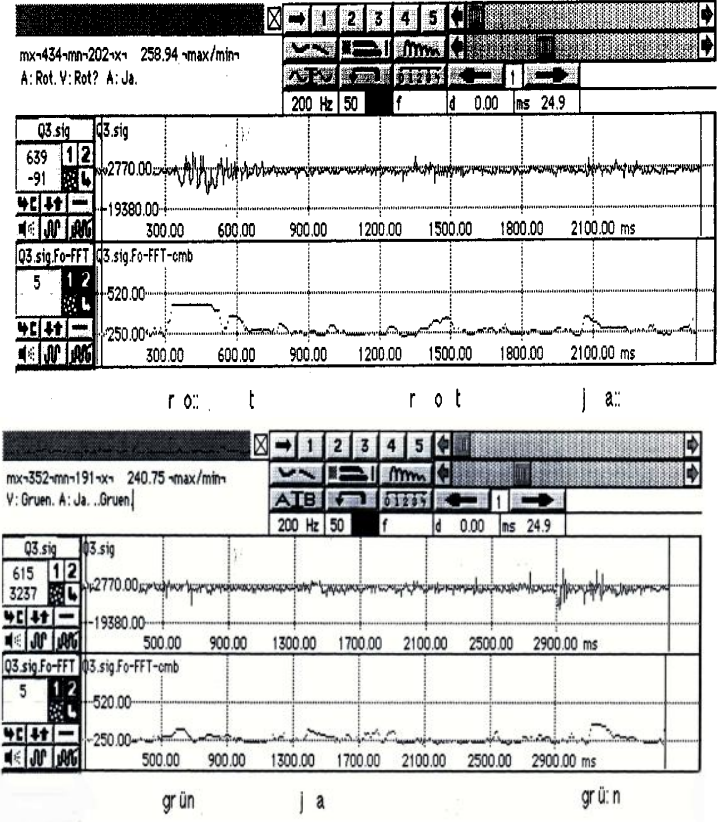

Fig. 4: Acoustic analysis of prosodic dialogue structure (two examples)

Intonation interpretation of dialogue responses (S1)

With regard to rhythm and tempo in the micro-dialogue (Fig. 4), one can observe quasi-nominations in responses (4A) and (6A). It is supported by the wave shape of the intonation contour of the utterance and long duration (4A), with the F0 $\max (434 \mathrm{~Hz})$ and maximal vowel [o] with duration $(300 \mathrm{~ms})$. Parallel quasi-response (6A) does not have such distinguished intonation characteristics as the situation is more important. The child is aware of incorrect nominations because response (8A) demonstrates the correct affirmative nomination. The intonation demonstrates the falling F0 contour at the end of the utterance, which is below its beginning (Lösungstiefe).

S2.

1E: // Was ist das? (What is this?)

2A://(Nen) Auto.(No, car.)

3E: // Ein Auto.(A car.)

4A: // Ja.(Yes)

5E: // Welche Farbe hat denn das Auto?

(What color is the car?)

6A: // Gelb.(Yellow.)

7E: // Gelb?(Yellow?)

8A: //'Ja.(Yes)

9E: // Is das nich blau? (Is it not blue?)

10A: // Ja ... blau. (Yes... blue.)

11E: // Blau.(Blue.) 
The structure of Situation 2 (successful communicative interaction)

\section{EXTLIP}

Interrogative (E:) - encouraging nomination

Declarative (A:) - reference utterance

Declarative (E:) - confirmation of the previous remark

Declarative (A:) - confirmation

Interrogative $(\mathrm{E})$ - natural change in the topical focus

Declarative (A:) - spontaneous incorrect nomination, referential utterance

Interrogative (E:) - repeated utterance, cross-reference

Declarative (A:) - confirmation of the previous remark

Interrogative (E:) - cross-reference with the correct nomination

Declarative (A:) - confirmation of the adult remark, agreement, self-correction

Declarative (E:) - reference utterance

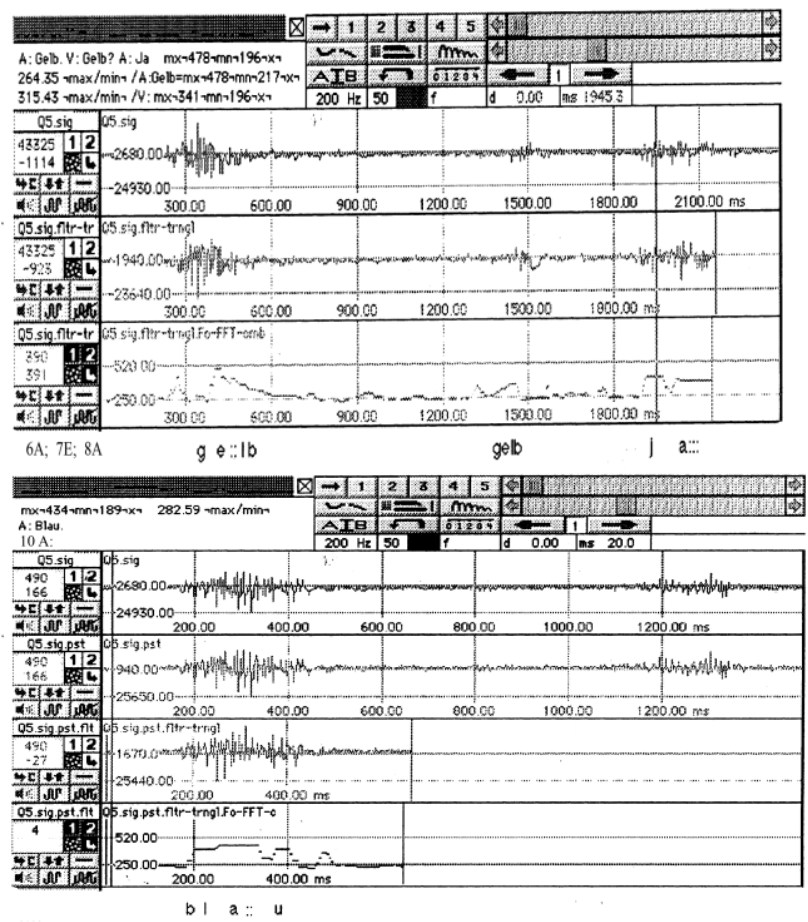

Fig. 5: Analysis of acoustic-prosodic features of responses (two examples)

Dialogue (S1) is identical to dialogue (S2) with respect to the same topical focus of the discourse and communication failures. The referential nominations improperly verbalized by a child account for it. Since the child is familiar with colors, as it was observed in earlier adequate nominations, the adult expresses surprise at the child's incorrect nominations. The nominations are incorrect as the child speaker has to agree with the adult speaker after the second incorrect naming, and it results in self-correction. The child demonstrates the positive mental attitude to communication.

\section{Intonation interpretation of dialogue responses (S2)}

The micro-dialogue has mixed temporal parameters. The adult speaker uses a speedy rate in the utterance. The child produces the response with high pitch of tone and longer accented stressed nuclear vowels. Responses (6A) and (8A) are incorrect nominations. At the supersegmental level, utterance $(6 \mathrm{~A})$ demonstrates the F0 maximum $(480 \mathrm{~Hz})$ with sharp change in contour of nuclear vowel center [e] and its relatively short duration (about 100ms). The word is characterized by the maximum value of intensity. Confirming response (8A) has the level tone of the nuclear vowel and its longer duration. The intonation contour tends to fall. It is known that falling melodic patterns can express such modal connotation as categorical assertion [8].

Thus, these intonation properties of the response make it clear that it is incorrect information and pitch change (10A) confirms it. This micro-dialogue has also longer pauses between the responses as well inside the phrases ( 4 seconds before the correct denotation [blau] ([blue])).

S3.

\section{$1 A: / / \ldots \ldots$}

((jucht))(exclaim with delight)

$2 \mathrm{~V}$ : // was ist das? (What is this?)

\section{A: // ein Quak Quak. (a quack, quack.)}

4V: // quak quak macht der: Wer is denn das? (What makes quack: What is it?)

\section{A: // Quak. (Quack.)}

6V: // is nen Frosch. (is a frog.)

7A: // ne quak.(No,quack.)

8V: // der quakt?(Does it quack?)

9A: //ja.(Yes.)

10V: // der FROSCH macht quak. (The frog quacks.)

$$
\text { 11A: // quak.(quack.) }
$$

In the interrogative question, "Was ist das?" (What is this?) (2V) adult speaker (V) uses a repeat, marking the previous remark with the help of "das" supposing that "quak quak" (quack quack) is a distinctive characteristic of the object. As utterance (5A) represents remark (3A) in a new way, it proves the fact of nomination. It becomes evident when child speaker (A) rejects the prompt and refuses to name the object "Frosch" (frog) insisting on "Quak"(quack). Dialogue (S3) demonstrates a successful communicative interaction by introductive (EXTLIP exposure) and identifying reference (object reference).

The structure of Situation 3(S3) 


\section{EXTLIP}

NVK (happiness of A:) - positive emotion after EXTLIP exposure shows a positive intention of (A): positive mental attitude to communication

Interrogative $(\mathrm{V}:)$ - encouraging to provide the verbal nomination of the denotate

Declarative (A:) - spontaneous quasi-response resulting in communication mismatch

Declarative + Interrogative (V:) - identification and correction of speech error of (A:); cross-reference by replacing interrogative "Was" ("What") with "Wer" ("Who")

Declarative (A:) - intentional quasi-response

Declarative (V:) - repeated correction of the wrong nomination of $(\mathrm{A})$

Declarative (A) - intentional quasi-response, deliberate rejection of the adult speaker remark

Interrogative $(\mathrm{V}:)$ - change in the focus to the function of the denotation

\section{Declarative (A:) - referential response}

Declarative (V:) - cross-reference, introducing and repeating the request of $(\mathrm{V})$ to denote the object

Declarative (A:) - intentionally incorrect nomination

Dialogue (S3) presents a quasi/pseudo-communication with the elements of speech and communication failures. The adult speaker utterances are deprived of their nomination functions (denoting the real object) and do not bring any result in interaction. The adult in the previous remarks does not consider the child's motivation in denoting (the child knows the meaning of the word "Frosh" (frog), but at the moment he is more attracted by the phonation of "Frosh" (frog) and transmits the referent too lately. The preschooler follows from the imitation of misunderstanding to intentionally incorrect nominations. At first sight, there is a successful communication, but the aim is not achieved: the adult speaker does not get an adequate answer to the initial question.

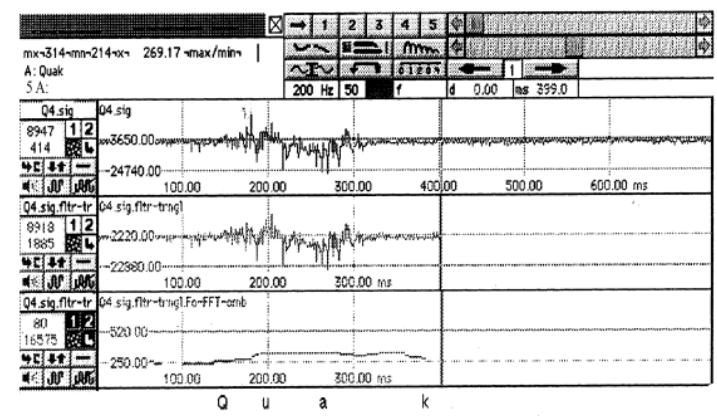

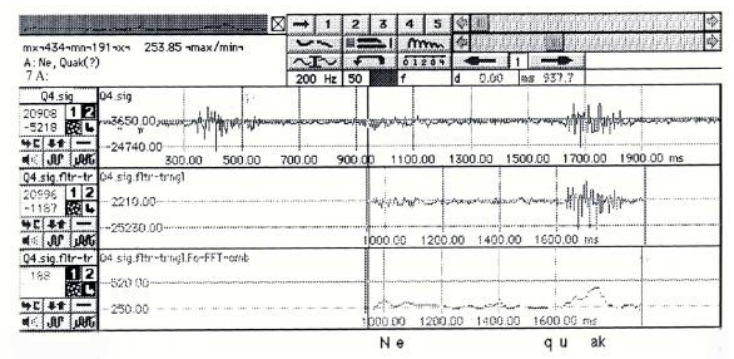

Figure 6: Acoustic analysis of prosodic dialogue structure

\section{Intonation interpretation of dialogue responses (S3)}

With regard to rhythm and tempo in the micro-dialogue, one can observe quasi-nominations in responses (4A) and (6A).

Responses (3A), (5A) and (7A) are incorrect nominations and present some moments of a role play. The animate object is not denoted by the word, but its phonation [der FROSCH macht quak] ([the frog makes quack]). Response (5A) is produced with more intensity and quite short duration of the nuclear syllable (about $100 \mathrm{~ms}$ ). The intonation contour line does not show big jumps. The F0 is mean, level, low $(270 \mathrm{~Hz})$. Unit [quak] ([quack]) has a strong intensity, with a sharp change in the contour and longer nuclear vowel center (more than $200 \mathrm{~ms}$ ).

\section{CONCLUSION}

Overall, the authors find it possible to conclude that:

1) quasi-questions (child-initiated questions) are mostly non information-seeking; a child is seeking an adult's attention and contact rather than information;

2) question-asking can present a playing activity when a child repeats an adult's questions; the child speaker seeks emotional contact with the adult speaker;

3) quasi-responses are manifested in intonation by combination of the duration, intensity and the pitch of tone;

4) age period $2.0-2.5,30 \%$ of questions and statements, demonstrates a conflict between the response form (syntactic structure and intonation) and nonverbal elements (child behavior);

5) the utterances $(100 \%)$ are addressed to adults;

6) since the addressant shows a demonstrative behavior, it signals deprivation; the child feels the need to make a contact with the addressee;

7) dialogue information field is stagnating and communication is interrupted;

8) stagnation in the ill-formed dialogue is repaired by cross-reference.

Thus, "anti-deprivation" function of child communication results in quasi-discourse in early ontogenesis.

\section{References}

[1] E.N. Vinarskaya, Age phonetics. Moscow: AST, 2005, 207p.

[2] E.N. Vinarskaya, Early child speech development and the problems of defectolkogy. Moscow: Education, 1987, 159p.

[3] T.G. Vinokur, The speaker and the listerner. Variants of communicative behavior. Moscow: Science, 1993, 171p.

[4] A.D. Koshelev and T.V. Chernigovskaya, "Logical behavior and language," in Communicative systems of animals and human language, iss.1. Moscow: Languages of slavic cultures, 2008, 416p. 
[5] A.A.Romanov, "Decription of communicative mismatches typology," in Problems of language functioning. Moscow: B.i., 1987, pp.78-109..

[6] M.L. Makarov, Foundations of the discourse theory. Moscow: Gnosis, 2003, 280p.

[7] O.M. Sedov, Discourse as suggestion. Irrational impact in interpersonal interaction. Moscow: Labyrinth, 2011, 336p.

[8] R.K. Potapova, Connotative paralinguistics. Moscow: MSLU, 1998, $67 \mathrm{p}$.

[9] P.K. Potapova, Language, speech, personality. Moscow: Languages of slavic cultures, 2006, 496p

[10] E.Yu. Protassova, Multilingualism in childhood. St. Peterburg: Zlatoust, 2005, $276 \mathrm{p}$

[11] A. Palviainen, E. Protassova, K. Mard-Miettinen, and M. Schwartz, "Two languages in the air: a cross-cultural comparison of preschool teachers' reflections on their flexible bilingual practices," in International Journal of Bilingual Education and Bilingualism. Vol. 19, Iss. 6, pp. 614-630, 2016.

[12] M.Schwartz, M. Minkov, E. Dieser, E. Protassova, V. Moin, and M. Polinsky, "Acquisition of Russian gender agreement by monolingual and bilingual children," in International Journal of Bilingualism, Vol. 19, Iss. 6, pp. 726-752, 2015.

[13] C. Lleo, M. Prinz, C. ElMogharbel, and A. Maldonado, "Early phonological acquisition of German and Spanish: A reinterpretation of the continuity issue within the principles and parameters model" in Children's Language, Vol. 9, C.E. Johnson and J. Gilbert, Eds. Mahwah, NJ: Lawrence Erlbaum, 1996, pp. 11-31.

[14] M. Kehoe and C. Lleo, The acquisition of syllable types in monolingual and bilingual German and Spanish children. 27th Annual Boston-University Conference on Language Development, 2003, pp. 402-413.

[15] C. Lleo and K. Demuth, "Prosodic constraints on the emergence of grammatical morphemes: Crosslinguistic evidence from Germanic and romance languages," in Proceedings of the 23rd Annual Boston University Conference on Language Development, A. Greenhill, $\mathrm{H}$. Littlefield, and C. Tano, Eds. Somerville, MA: Cascadilla Press, 1999. pp. 407-418.

[16] G. Hickok, U. Bellugi, and E.S. Klima, "Sign language in the brain," in Scientific American, Vol. 284, Iss. 6, pp. 58-65, 2001. 